\title{
Social and psychological attitudes of technical higher educational institution students
}

\author{
Olga Beluzhenko ${ }^{1, *}$, Sergey Popov ${ }^{2}$, Sergey Kuren², Nikolay Dontsov², and Sergey \\ Timofeev $^{2}$ \\ ${ }^{1}$ South-Russian Institute of Management - branch of Russian Academy of National Economy and \\ Public Service under the President of the Russian Federation, 70, Pushkinskaya Str., Rostov-on-Don, \\ Russia \\ ${ }^{2}$ Don State Technical University, 1, Gagarin sq., Rostov-on-Don, Russia
}

\begin{abstract}
The article presents the results of the first time study of the features of social and psychological attitudes of students enrolled in technical higher educational institution in various training programs using the O.F. Potyomkina method of diagnostics of social and psychological attitudes of the personality in motivational-requirement sphere. By means of correlation analysis the interrelations have been established between social and psychological attitudes within the every training program. It has been found, that for the students of "Maintenance and repair" training program the structure of social attitudes has a holistic character, whereby redistributes the energy of the most pronounced areas in frustrated sphere, suggesting a more harmonious process of personal development of future specialists. It has been found that for the students of training programs "Organization and safety" and "Ground transportation" the structure of attitudes has either hard closed areas or isolated ones, which makes the energy exchange be implemented in the framework of the motivational sphere and indicates the disharmonious process of personal development of future specialists. It has been found that surveyed students of all training programs do not have a confrontation between "altruism" and "egoism", which indicates a certain personal immaturity of the respondents. Recommendations are formulated for curators of student groups and teachers working with students in these training programs. Our proposed research algorithm can be recommended for implementation in a higher educational institution of any training program as a motivational monitoring.
\end{abstract}

\section{Introduction}

In modern conditions, it is especially relevant to obtain objective information about whether the chosen profession corresponds to the student's personal interests and inclinations and how exactly the personal and professional formation of the future specialist is carried out. Therefore, even at the stage of higher education, it is necessary to identify such structural changes in the personality and, accordingly, to study the formation of such personal neoplasms that determine the professional and personal formation of the future specialist. In

\footnotetext{
* Corresponding author: ocdod-bel@mail.ru
} 
this regard, the research of students ' socio-psychological attitudes as part of the structure of their professional consciousness is of particular importance.

A thorough study of the literature allows us to offer the following list of works devoted to the study of the socio-psychological attitudes of student youth.

Thus, the authors' works [1-4] are devoted to the study of university students' attitudes. The authors of the works [5-8] were engaged in the study of attitudes and beliefs of medical students. Lydia Hernandez-Lopez et al. [9] explored the ethical aspects of socialization and the attitudes of business school students. There are works [10-11] devoted to the study of perception, motivation and attitudes of senior students. Finally, a number of authors [12-15] have devoted their research to reviewing students' learning strategies, formed in accordance with their personal attitudes.

From the above list it follows that at present the peculiarities of the social and psychological attitudes of students namely of technical universities can be attributed to the poorly studied area of psychological knowledge.

Based on this circumstance, the purpose of this study was to study the specifics of the social and psychological attitudes of students studying at a technical university.

Research objectives:

1. In the course of the review of the scientific literature to carry out an analysis of the current situation related to the study of the socio-psychological attitudes of student youth.

2. To investigate the relationship between the socio-psychological attitudes of students and their training program.

3. To develop recommendations for adjusting the process of professional and personal formation of a future specialist.

\section{Materials and methods}

The study, which was carried out in September-October 2018, involved 43 students of the «Transport, service and Maintenance » faculty of Don State Technical Universuty, Rostov on - Don. The subjects ranged in age from 18 to 24 years.

The distribution of subjects in the training programs was as follows:

- "Maintenance and repair of motor transport" - 25 people;

- "Traffic organization and safety" - 5 people;

- "Ground-based transport and technological means" - 13 people.

As a research tool, we had been used the method of O. F. Potemkina [16], which have been directed at identifying the degree of expression of socio-psychological attitudes to "altruism - egoism", "process - result", "freedom - power", "labor - money". For each of the above settings, the test subject can score from 1 to 10 points. The essence of this technique is that it allows you to diagnose the degree of severity and interrelation between each other of socio-psychological attitudes not only in an individual, but also in a group of people. In general, this technique is an example of a subjective psychological test and is a multifactorial questionnaire consisting of two parts, the processing of which leads to the results on eight dependent variables measured in a metric scale, which, as is known, provides researchers with the widest set of possible data processing methods.

\section{Results and discussion}

Indicators of the severity of socio-psychological attitudes of students in the training programs are presented in table 1 . 
Table 1. Indicators of the socio-psychological attitudes severity among the students of various training programs (in average points).

\begin{tabular}{|c|c|c|c|c|}
\hline No. & $\begin{array}{c}\text { The name of } \\
\text { severity }\end{array}$ & $\begin{array}{c}\text { Maintenance and } \\
\text { repair }\end{array}$ & $\begin{array}{c}\text { Organization and } \\
\text { safety }\end{array}$ & $\begin{array}{c}\text { Ground } \\
\text { transportation }\end{array}$ \\
\hline $\mathbf{1}$ & Process & $5.64 \pm 1.82$ & $5.60 \pm 1.52$ & $5.77 \pm 2.01$ \\
\hline $\mathbf{2}$ & Result & $6.04 \pm 1.81$ & $5.80 \pm 0.84$ & $6.08 \pm 1.50$ \\
\hline $\mathbf{3}$ & Altruism & $5.54 \pm 2.23$ & $3.60 \pm 2.41$ & $5.31 \pm 1.84$ \\
\hline $\mathbf{4}$ & Egoism & $5.24 \pm 2.13$ & $5.80 \pm 1.79$ & $4.00 \pm 2.04$ \\
\hline $\mathbf{5}$ & Labour & $5.46 \pm 2.21$ & $6.20 \pm 1.48$ & $6.38 \pm 1.98$ \\
\hline $\mathbf{6}$ & Freedom & $6.54 \pm 1.84$ & $7.40 \pm 0.89$ & $6.38 \pm 1.45$ \\
\hline $\mathbf{7}$ & Power & $4.38 \pm 2.07$ & $4.80 \pm 3.70$ & $3.54 \pm 1.66$ \\
\hline $\mathbf{8}$ & Money & $4.72 \pm 2.17$ & $4.00 \pm 2.00$ & $3.12 \pm 2.10$ \\
\hline
\end{tabular}

The next stage of our work was to establish relationships between socio-psychological attitudes within the focus groups corresponding to each training program. To do this, a correlational analysis of the results of the empirical study has been carried out separately for each focus group using the SPSS 13 for Windows program. Correlation analysis data are presented in tables 2, 3, and 4 (meaningful correlations are placed only).

Table 2. The correlation links between socio-psychological attitudes for the focus-group «Maintenance and repair».

\begin{tabular}{|c|c|c|c|c|}
\hline \multirow{2}{*}{ No. } & \multirow{2}{*}{$\begin{array}{c}\text { The correlation } \\
\text { dyad }\end{array}$} & \multicolumn{2}{|c|}{ Correlation coefficient } & \multirow{2}{*}{$\begin{array}{c}\text { Bilateral } \\
\text { p-significance level }\end{array}$} \\
\hline & & Pearson's & Spearman's & \\
\hline 1 & result - power & & $0.478^{*}$ & 0.016 \\
\hline 2 & altruism - labour & & $0.444^{*}$ & 0.026 \\
\hline 3 & altruism - freedom & & $0.509^{* *}$ & 0.009 \\
\hline 4 & altruism - money & & $-0.461 *$ & 0.020 \\
\hline 5 & egoism - power & $0.495^{*}$ & & 0.012 \\
\hline 6 & egoism - money & & $0.568^{* *}$ & 0.003 \\
\hline
\end{tabular}

* - significant correlation at the 0.05 level.

** - significant correlation at the 0.01 level.

Table 3. The correlation links between socio-psychological attitudes for the focus-group «Organization and safety».

\begin{tabular}{|c|c|c|c|}
\hline No. & The correlation dyad & $\begin{array}{c}\text { Spearman's correlation } \\
\text { coefficient }\end{array}$ & $\begin{array}{c}\text { Bilateral } \\
\text { p-significance level }\end{array}$ \\
\hline 1 & egoism - labour & $0.921^{*}$ & 0.026 \\
\hline 2 & egoism - freedom & $-0.918^{*}$ & 0.028 \\
\hline 3 & labour - freedom & $-0.918^{*}$ & 0.028 \\
\hline
\end{tabular}

* - significant correlation at the 0.05 level.

** - significant correlation at the 0.01 level.

Table 4. The correlation links between socio-psychological attitudes for the focus-group «Ground transportation».

\begin{tabular}{|c|c|c|c|c|}
\hline \multirow{2}{*}{ No. } & The correlation dyad & \multicolumn{2}{|c|}{ Correlation coefficient } & Bilateral \\
\cline { 3 - 4 } & & Pearson's & Spearman's & $\begin{array}{c}\text { p-significance } \\
\text { level }\end{array}$ \\
\hline 1 & result- altruism & & $-0.756^{* *}$ & 0,003 \\
\hline 2 & altruism - labour & $0.650^{*}$ & & 0,016 \\
\hline 3 & egoism - money & & $0.573^{*}$ & 0,041 \\
\hline
\end{tabular}

* - significant correlation at the 0.05 level.

** - significant correlation at the 0.01 level. 
As the mathematical equivalent of the links between socio-psychological attitudes, we used indicators of significant correlation between the numerical values of the severity of attitudes. In all cases, we calculated the Spearman's correlation coefficient. In some cases, tables 2 and 4 also include Pearson's correlation coefficient (the focus-groups' sizes allow this). The correlation pleiades reflecting the results obtained are shown on figures 1, 2 and 3.

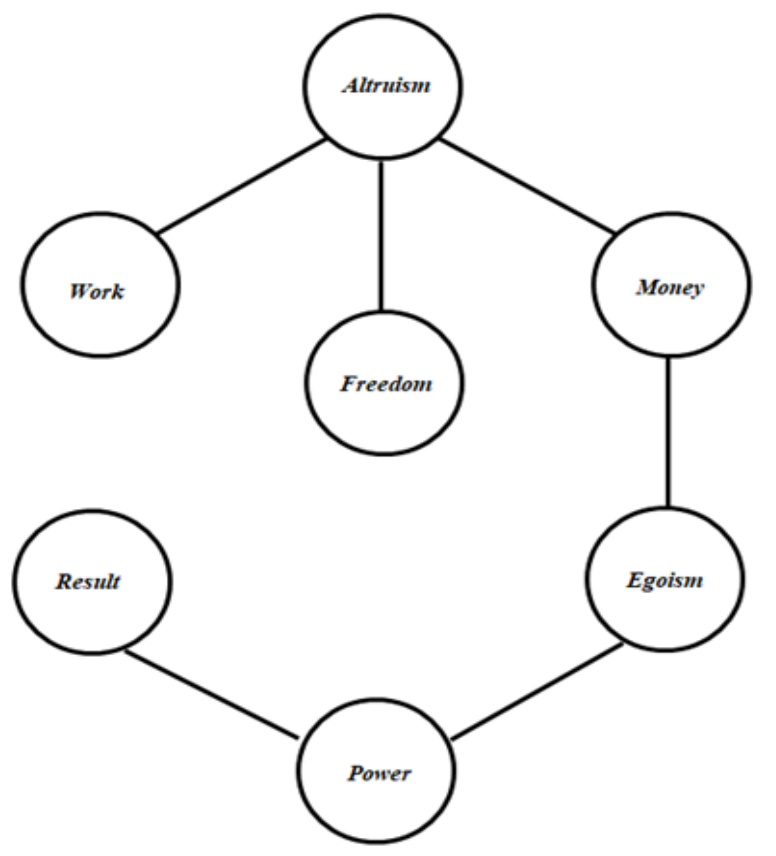

Fig. 1. Scheme of the relationship of socio-psychological attitudes of students studying for the "Maintenance and repair" training program*.* The correlation "altruism" - "money" - inverted. All other correlations - direct.

From the data presented on fig. 1, it follows that in the focus-group of students studying in "Maintenance and repair" training program there are the following groups of attitudes: "focus on altruism" - "focus on money" - "focus on egoism" - "focus on power" - "focus on result" and " focus on labour" - "focus on altruism" - "focus on freedom".

It should be noted that the two above-mentioned substructures include both the most pronounced focuses ("focus on result", focus on freedom") and the most frustrated focuses ("focus on money", focus on power "). At the same time, the structure of the correlation pleiad does not have a gap, i.e. it is a single whole. This suggests that in the structure of sociopsychological attitudes of students studying for the "Maintenance and repair" training program, there is a redistribution of mental energy due to the coexistence of pronounced and frustrated attitudes; at the same time, the energy of the first ones helps to overcome the difficulties arising in the second ones. It is in this focus-group that attitudes are expressed most evenly, and the structure shows the largest number of significant correlations. At the same time, it should be noted that the moral dichotomy "altruism - egoism" is not formed among students of this training program, which is evidence of their relative personal immaturity. 


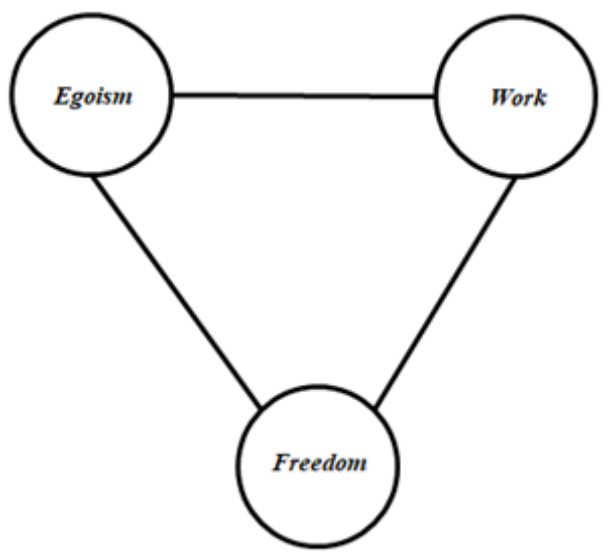

Fig. 2. Scheme of the relationship of socio-psychological attitudes of students studying for the "Organization and safety" training program*.* The correlation "egoism" - "labour" - direct. All other correlations - inverted.

From the data presented in figure 2, it follows that in the focus-group of students studying for the "Organization and safety" training program, there is a single group of attitudes: "focus on egoism" - "focus on labour" - "focus on freedom". This group has rigid cyclic character and contains two pronounced orientations ("focus on labour " and "focus on freedom"), which energetically feed the more weakly expressed " focus on egoism ".

At the same time, it should be emphasized that the three most "scarce" settings ("focus on altruism", "focus on money" and "focus on power") are not only not part of the groups under consideration, but totally ignored the "collective unconscious" of students studying for the "Organization and safety" training program. In this group of students, the frustrated zone is not just isolated, but, in fact, "erased", which is a manifestation of their primitive and ineffective defense mechanism created in the motivational sphere.

The presence of such problematic moments' ignorance and, in addition to this, the already familiar to us lack of formation of the "altruism - egoism" dichotomy indicate the immaturity of the individual and a fairly strong orientation towards satisfying their own (egoistic) needs among students of this training program.

From the data presented in figure 3, it follows that in the focus-group of students studying for the «Ground transportation» training program there are the following groups of attitudes: "focus on result" - "focus on altruism" - "focus on labour" and "focus on egoism" - "focus on money".

It should be noted that the first of the two mentioned substructures includes the two mostly pronounced focuses ("focus on result" and "focus on labour"), which energetically "feed" the less pronounced "focus on altruism". Unfortunately, the structure of this correlation pleiad has a gap, that is, in fact, it consists of two parts, since the second substructure ("egoism" "money") is located in isolation (fig. 3). 

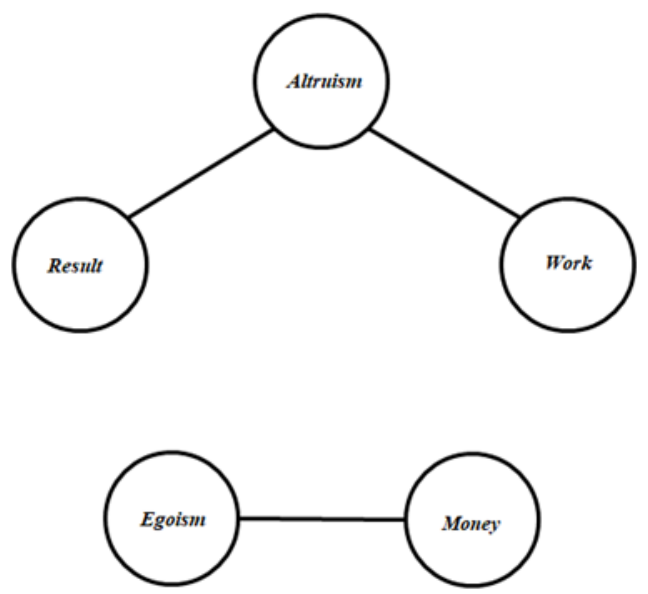

Fig. 3. Scheme of the relationship of socio-psychological attitudes of students studying for the «Ground transportation» training program*.* The correlation "altruism" - "money" - inverted. All other correlations - direct.

Thus, in the needs' sphere of students studying for the "Ground transportation» training program there is a separate structure for successfully implemented installations and a separate one for installations that are frustrated ("egoism" and "money"). Perhaps this gap is a manifestation of the functioning of protective mechanisms on a background, in general, of an insufficiently developed motivational structure. Along with this, it is necessary to note the same lack of formation of the moral dichotomy "altruism - egoism" with students of this training program, which is evidence of their relative personal immaturity.

It is obvious that harmonious personal development determines the success and productivity of future professional activities of students. Here, an important role belongs to University employees who are in direct contact with students - curators of student groups and teachers. It is subject-subject interaction in the educational space of the University that ensures the active involvement of students in the development of not only subjectdisciplinary, but also valuable experience of self-knowledge and self-development.

The diagnostically identified frustrated features of the content of socio-psychological attitudes of students of various training programs should be known to curators and teachers working with these student groups, should cause them to engage in value-semantic work, to harmonize the personal development of their wards. In particular, according to the results of this study, the object of close attention on the part of curators and teachers should be the autocratic and monetary motivation of all students surveyed. In addition, students of the "Organization and safety" training program should develop the altruistic motivation, and students of the "Ground transportation" training program should develop the ambitious motivation. The subject of a separate concern should be the work on the formation of the ethical dichotomy "altruism" - "egoism" in all the surveyed students. As tools for this activity, we can recommend: a) problem-based search dialogues; b) educational discussions; c) heuristic conversations; d) specific situations analysis.

\section{Conclusions}

1. Using the method of diagnostics of socio-psychological attitudes of the individual in the motivational and needs sphere by O. F. Potemkina for the first time have been investigated the features of socio-psychological attitudes of students studying at the technical university in various training programs. 
2. Using the method of correlation analysis, the relationships between socio-psychological attitudes within each focus-group were established.

3. It was found that the structure of socio-psychological attitudes of students studying fot the "Operation and repair" training program has a holistic character, due to which energy is redistributed from the most pronounced areas to the frustrated areas, which indicates a harmonious process of personal development of future specialists.

4. It was found that students studying fot the "Organization and safety" and "Ground transportation" training programs have a structure of socio-psychological attitudes that either has a rigid closed character or has isolated areas, which does not allow energy exchange to be realized within the motivational sphere and indicates a disharmonious process of personal development of future specialists.

5. It was found that the surveyed students of all training programs do not have a contrast between "altruism" and "egoism", which indicates a certain personal immaturity of the respondents.

6. Recommendations are formulated for curators of student groups and teachers working with students in these training programs.

7. The research algorithm proposed by us can be recommended for implementation in higher education institutions of any training programs as a motivational monitoring.

\section{References}

1. E.M. Albay, Social Sciences \& Humanities Open 1(1), 100006 (2019)

2. S. Salim, Procedia - Social and Behavioral Sciences 5, 426-430 (2010)

3. L.E. Ercan, Procedia - Social and Behavioral Sciences 2(2), 1814-1819 (2010)

4. R.M. Shamionov, M.V. Grigoryeva, A.V. Grigoryev, Procedia - Social and Behavioral Sciences 7(112), 323-332 (2014)

5. M.K. Grace, Social Sciences \& Medicine Yuly 184, 84-98 (2017)

6. T.C. van den Boogaard, P.F. Roodbol, I.E. Poslawsky, Y. ten Hoeve, Nurse Education in Practice May 37, 124-131 (2019)

7. V. Gritsenko, V. Konstantinov, A. Reznik, R. Isralowitz, Complementary Therapies in Medicine 48, 102274 (2020)

8. T.-I. Tsai, L. Luck, D. Jefferies, L. Wilkes, Collegian 3(25), 341-345 (2018)

9. L.E. Hernández-López, F.R. Álamo-Vera, J.L. Ballesteros-Rodrígues, P. De Saá-Pérez, The International Journal of Management Education 1(18), 100363 (2020)

10. M. Saini, A. Kumar, G. Kaur, Procedia Computer Science 167, 185-192 (2020)

11. S.R.S. Mahadi, N.N. Jamaludin, R. Johari, I.N.F.M. Fuad, Procedia - Social and Behavioral Sciences 219, 472-479 (2016)

12. D. Çetingöz, N. Özkal, Procedia - Social and Behavioral Sciences 1(1), 1905-1913 (2009)

13. H. Çalişkan, G. Kilinç, Procedia - Social and Behavioral Sciences 55, 47-56 (2012)

14. X. Hu, F.K.S. Leung, G. Chen, International Journal of Educational Research 92, 135 144 (2018)

15. O.V. Beluzhenko, S.G. Kuren, S.I. Popov, N.S. Dontsov, XIII International Scientific and Practical Conference «State and Prospects for the Development of Agribusiness INTERAGROMASH 2020»: E3S Web of Conferences 175, 15017 (2020) doi.org/10.1051/e3sconf/202017515017 
16. M. Gagné, The Oxford Handbook of Work Engagement, Motivation, and Self Determination Theory (Oxford University Press, New York, 2014) 